\title{
Teaching and Learning Transformative Processes (The Winter School Program)
}

\author{
Nino Sozashvili ${ }^{1, *}$, Jan Bohm², Tyrone Bynoe ${ }^{3}$, Irma Barbakadze ${ }^{4}$ \\ ${ }^{1}$ Department of Higher Education, Telavi State University, Georgia \\ ${ }^{2}$ Department of Comparative Education, University of Education Upper Austria, Austria \\ ${ }^{3}$ Department of Education, University of Michigan-Flint, USA \\ ${ }^{4}$ American Councils for International Organization, USA
}

Copyright (C) 2016 by authors, all rights reserved. Authors agree that this article remains permanently open access under the terms of the Creative Commons Attribution License 4.0 International License

\begin{abstract}
Scientific studies never replace or supplant subjective theories, but in the best case, enter a productive symbiosis; they can contribute to reflecting on and understanding one's own assumptions and thereby make them available to change. It is pedagogically sensible to address this tension between scientific and subjective theory, and thereby make pedagogical reflection accessible. For this reason, we bring forward the argument that practical experience in the field of education must precede a course of study using the scientific, theory-oriented approach to teacher training. This turns conventional education theory upside down: normally a well-grounded scientific education is required first, followed by cautious experiences in practical areas. Consequently, a valuable source of pedagogical knowledge is underrated, and regretfully also often discredited. The awareness and reflection of one's own subjective theories have to, however, be an integral part of any educational discussion of pedagogy and learning. The idea of allowing educational experiences without previous scientific education was tested in the Winter School Program, "Modern Teaching Methods," at Telavi State University. The participants in the Winter School Program were students from different disciplines. None had previously studied in the field of education. The participants were thus highly heterogeneous with respect to their educational training, but homogeneous with respect to their inexperience in educational studies. The interaction of the participants with theoretical assumptions of and models of pedagogy, on the one hand, and their own experiences, on the other, generated a productive tension that makes continuing related learning very probable.
\end{abstract}

Keywords Education, Transformation, Teaching, Learning

\section{Introduction}

Teaching and learning by experience -- whether through kinesthetic, simulation, role-playing, field experience, and the like -- are basic to all human interactions. This kind of teaching and learning exists prior to any systematic reflection about ways to convey or acquire knowledge (cf. Gadamer, 1960). Anyone serious thinker about education is aware of this simple fact. In other words, insight concerning education does not require formal training in education as a social scientific discipline. In fact, "common sense" and intuitive understandings regarding teaching and learning by those without a background in the "science" of education produce what may be called subjective theories of education, and these may be differentiated from formal, scientific theories. So-called subjective theories influence our perception and give us direction in everyday life.

Subjective theories, however, can stimulate scientific reflections. Subjective approaches to education embrace clinical pedagogy and experiential learning, whereas scientific teaching and learning is based on abstract theory rather than application. Furthermore, subjective theories and scientific reflections are complementary. That is to say, so-called pre-theoretical suppositions (subjective theories) are no less valid that scientifically derived theories. Both types of theory have their place and are related to each other. The efficacy of subjective theories of education has been confirmed again and again. It can be demonstrated that the perception and explanation of certain phenomena, such as teaching, learning, conflict resolution, role expectation, evaluation and communication, are guided by subjective assumptions rather than by scientific theories emphasized in formal education training programs. To interpret this reality as a declaration of the bankruptcy of scientific educational training-would be to miss the point being made here, which is the usefulness of a subjective-scientific theory symbiosis.

Georgia's education system, along with education systems in other developing countries and particularly those in post-Soviet countries, is experiencing significant changes. Traditional scientific approaches such as teacher-centered instruction (lectures) and rote-memorization are being replaced by new innovative pedagogical techniques that 
reflect the principles of subjective educational theories. Traditional learning practices are accompanied by new thinking about instructional methods as part of Georgia's modernizing process. Innovative pedagogy, also labeled constructivist, will bring Georgia's educational system in line with that in the western world. The government is making critical changes in its higher education curriculum in the areas of administration, management and teacher preparation programs.

Scientific studies never replace or supplant subjective theories; in the best case scenario, these studies enter a productive symbiosis. They can contribute to reflecting on and understanding one's own assumptions and thereby make them available to change. Only after a practical experience in the field of education has been made should a scientific theory-oriented education follow. This turns conventional education theory upside down: Normally, a well-grounded scientific education is required first, followed only afterward by cautious experiences in practical areas; a clear leading role of scientific theories before the practice is assumed. In addition, subjective theories that are always present are ignored or simply negated. Consequently, a valuable source of pedagogical knowledge is underrated, and regretfully also often discredited. The awareness and reflection of one's own subjective theories has to, however, be an integral part of any educational discussion of pedagogy and learning. Innovative pedagogy or constructivism, in other words, must be embraced.

\section{Practical Implementation}

The idea of allowing educational experiences without previous scientific education was tested in the Winter School Program, namely "Modern Teaching Methods" at the Telavi State University during February 7, 2014 to February 16, 2014. The participants in the Winter School Program were students from different disciplines. None of them, however, had ever taken courses in education. The participants were thus extremely varied with respect to their previous training, but homogeneous with respect to their total unfamiliarity with the field of education.

As stated above, the participants had practical experiences in the field of teaching during the lectures of the Winter School Program. The topics of the Winter School Program, Learning in the 21st Century, New Methods in Teaching, Theories of Teaching and Learning, Teaching Simulation, etc., provided participants with an opportunity to acquire new areas of knowledge and at the same time combine them with, and respectively reflect on, their prior everyday experiences. The methodological approaches of all presentations in the Winter School Program can be summarized as an intentional endeavor to promote the concept of constructivism. Constructivism in its educational orientation is like no other theoretical presupposition applicable to thinking about learning and teaching. Constructivism values, supports, and generates the idea of learning as self-appropriation and synthesis of the world; it validates constructs of reality that flow from ordinary human observations. The following principles of constructivist-driven didactics were used in various combinations as part of the Winter School Program:

- subject orientation

- connecting to the previous experiences of the participants

- change of social structures

- large share of social work structures (team work, project work)

- generative topics

- action orientation

- regular feedback

- reflexivity (see Siebert 2008; Arnold/Tutor 2007)

The principles and methods that have been referred to were supported by a focus on new media in the teaching-learning process. It was found that the above-mentioned constructivist features can be reinforced through the use of web-based and electronic media. This leads to a double learning output. Students' own learning processes are supported and encouraged. Additionally, through the use of new teaching and learning technologies, students can gain "media competence" as an automatic benefit. The observation of the activities of the participants during the Winter School Program confirms the assumptions of constructivism:

- Participants preferred collaborative learning environments.

- Discussions were particularly intense when they could be connected to one's own experiences.

- The discussions and learning outcomes often related to future areas of occupation or problem areas, which supports the assumption that the relationship between learning contents plays an important motivational role in learning.

- Content incentives by the lecturers are assimilated and are interpreted in a constructive and critical discussion process and further developed based on individual formulation of questions.

- This does not result in a passive reception of the presented content, but in an active acquisition and processing process.

- Through the reflected experience that constructs knowledge, confidence is developed by the participants that learning is not a causal product of teaching, but always a personal achievement of the learner, which can, however, be initiated and supported by stimulation and motivation on the teacher's part.

- Thus, the new role of the teacher as a learning consultant, expert and co-learner has become clear and can be reflected upon.

As already mentioned above, the "Modern Teaching Methods" sessions of the Winter School Program, funded by the Ministry of Education and Science of Georgia, were successfully implemented at Telavi State University. The 
goal of this Winter School was to raise awareness for a select group of students regarding the effective usage of modern methods and the information-communication technologies that can easily accelerate the learning process.

In our opinion, the quality of education depends on the skills-set of teachers. It was important that the Winter School Program unified qualified experts and possible teacher-recruits who formulated recommendations that contributed to the authoring of a new course syllabus known as "Teaching Innovative Methodology." This new course syllabus galvanized the discourse of lectures and focus groups between experts and students on contemporary and innovative pedagogy as a contribution to the training of future teachers in the Democratic Republic of Georgia.

\section{Summary Descriptive Statistical Findings}

The Winter School Program particularly included lectures and lesson-simulations designed to illustrate the practical usage of acquired information. Students were also evaluated on an end-of-seminar assessment concerning how well they internalized an understanding of teaching methods introduced through the seminars. An example of actual student performance is displayed in Table 1 and Figure 1 featuring a descriptive statistical report of how students exhibited a high measure of content validity during the lecture on Contrasting Teaching and Learning Methods:

Table 1. Descriptive Statistical Summary of Student Performance during Teaching and Learning Seminar

\begin{tabular}{|c|c|}
\hline Mean & 95 \\
\hline Mode & 100 \\
\hline Min & 70 \\
\hline Max & 100 \\
\hline
\end{tabular}

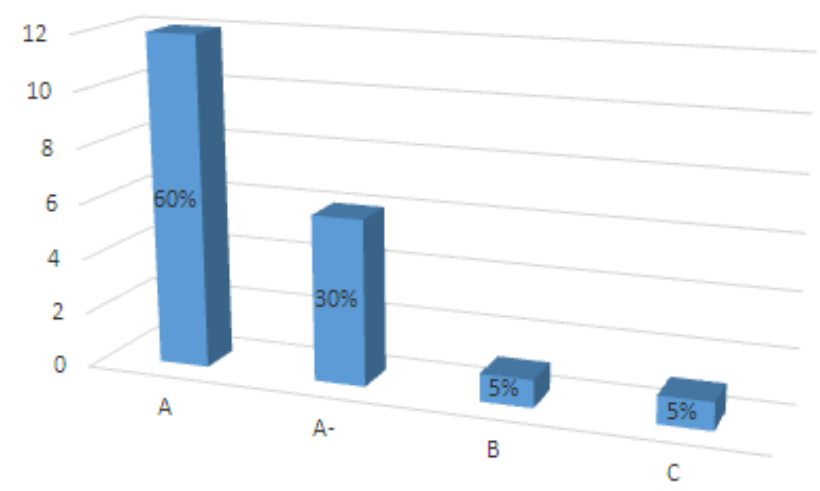

Figure 1. Winter School 2014 Student Performance Summary from Contrasting Teaching and Leaning Seminar

Since a correlation of .80 is a strong measure of content validity and since the class mean constitutes a correlation of .95 - with only 1 out of 20 students scoring below the expected level of performance -- as depicted by Figure 2 below, it stands to reason that student performance reflected the effectiveness of teaching and learning during this lecture. Simply stated, this impressive measure of content validity reinforced the high descriptive statistical findings regarding Winter School student performance reported in Table 1.

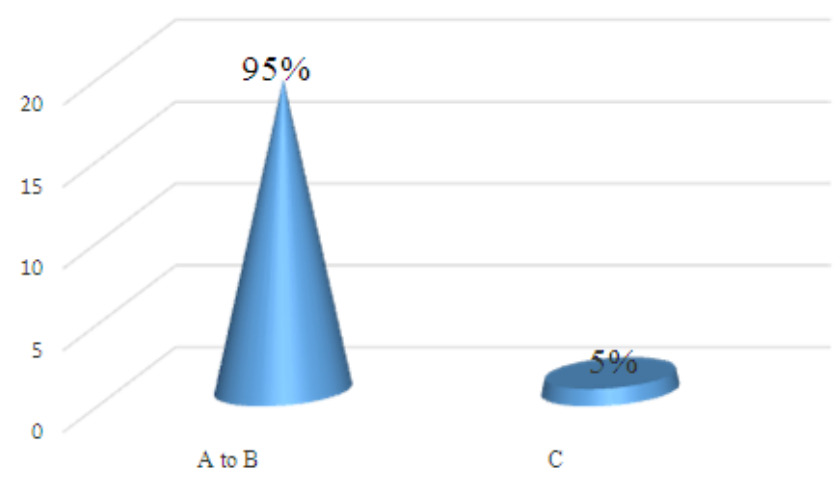

Figure 2. Winter School 2014 Summary of Student Performance in Contrasting Teaching and Leaning Seminar by Percent

\section{Conclusions}

Overall, it was found that the use of research-based theories about learning and teaching -- when compared to participant's previous traditional educational experiences propelled students to consider teacher education as a possible career. In addition, the interactive exchanges that participants had with student colleagues regarding other empirical research findings as well as with the examination of scientific theories heightened student reflection to unprecedented levels; these lively encounters are hardly found in university courses in education studies within Georgia.

The interaction of the participants with theoretical assumptions and models of pedagogy and their own experiences generated a productive tension that makes the continuity of learning very probable. It was also clear that effective forms of learning occurred in heterogeneous class configurations featuring students from different disciplines, which accelerated the pace of learning in both formal (lectures, seminars) and also informal learning settings (e.g. the Internet). More profoundly, the use of new IC technology makes it clear that the importance of informal learning (see Council of the EU 2009) continues to grow and can be supported by targeted use of new media during student coursework in the field of education.

For future endeavours, advanced courses or educator preparation programs should connect to the vibrant student experiences of the Winter School Program on "Modern Teaching Methods." This means that students should gain practical experiences in the field of practice alongside theoretical participation in educational sciences and the psychology of learning. In the field of education, value must be placed on making these experiences distinct encounters 
promoting pedagogical reflection in conjunction with conventional theory.

\section{REFERENCES}

[1] Arnold, R \& Gomez C. Grundlinien einer Ermöglichungsdidaktik. Augsburg, Germany: Ziel. 2007.

[2] The Council of the European Union. Council Conclusions of
12 May 2009 on a strategic framework for European cooperation in education and training ('et 2020'). OJ. [Internet] 2009. 52(1) [pp. 1-10]. Available from: http://eur-lex.europa.eu/legal-content/EN/TXT/PDF/?uri=OJ :C:2009:119:FULL\&from=EN (Accessed on December 22, 2015)

[3] Gadamer, H.-G. Wahrheit und Methode. Grundzüge einer philosophischen Hermeneutik, $2^{\text {nd }}$ Edition. Translation. New York: Crossroad. 2004.

[4] Siebert, H. Konstruktivistisch lehren und lernen. Augsburg, Germany: Ziel. 2008. 